\title{
Academic Emotions in Students' Self-Regulated Learning and Achievement: A Program of Qualitative and Quantitative Research
}

\author{
Reinhard Pekrun, Thomas Goetz, and Wolfram Titz \\ Department of Psychology \\ University of Munich, Germany \\ Raymond P. Perry \\ Department of Psychology \\ University of Manitoba, Canada
}

\begin{abstract}
Academic emotions have largely been neglected by educational psychology, with the exception of test anxiety. In 5 qualitative studies, it was found that students experience a rich diversity of emotions in academic settings. Anxiety was reported most often, but overall, positive emotions were described no less frequently than negative emotions. Based on the studies in this article, taxonomies of different academic emotions and a self-report instrument measuring students' enjoyment, hope, pride, relief, anger, anxiety, shame, hopelessness, and boredom (Academic Emotions Questionnaire [AEQ]) were developed. Using the AEQ, assumptions of a cognitive-motivational model of the achievement effects of emotions, and of a control/value theory of their antecedents (Pekrun, 1992b, 2000), were tested in 7 cross-sectional, 3 longitudinal, and 1 diary study using samples of university and school students. Results showed that academic emotions are significantly related to students' motivation, learning strategies, cognitive resources, self-regulation, and academic achievement, as well as to personality and classroom antecedents. The findings indicate that affective research in educational psychology should acknowledge emotional diversity in academic settings by addressing the full range of emotions experienced by students at school and university.
\end{abstract}

In the following analysis, we present an overview of our research on students' academic emotions. This research originated through Reinhard Pekrun's interests in students' test anxiety and motivation, and Raymond Perry's studies on academic control and motivation (e.g., Pekrun, 1991, 1992a; Perry, 1991; Perry \& Magnusson, 1989). Within the perspective of test anxiety and motivation research, we have found that test anxiety has been researched extensively since the beginning of the 1950s (Mandler \& Sarason, 1952) and even prior to that (cf. Stengel, 1936), whereas students' academic emotions, other than anxiety, have been largely neglected. The only major exception is the attributional research on achievement emotions undertaken by Weiner (cf. Weiner,

Requests for reprints should be sent to Reinhard Pekrun, Department of Psychology, University of Munich, Leopoldstrasse 13, 80802 Munich, Germany. E-mail: pekrun@edupsy.uni-muenchen.de
1985). Based on innovative theorizing, this research has produced a sizable number of studies as well as consistent, cumulative empirical evidence on the cognitive antecedents of achievement-related emotions.

Table 1 presents the results of a literature search of relevant studies. For the time span from 1974 to 1990, this search was originally published in Pekrun and Frese (1992) and was updated here for the decade of the 1990s, using the PsycINFO database. The search extends beyond the educational domain and includes any empirical studies linking the emotions listed in Table 1 to the topics of learning, test, performance, work, or achievement. It appears that test anxiety has continued to attract many researchers, whereas other achievement-related emotions have received much less attention. This pertains to negative emotions other than just anxiety, but even more so to positive achievement-related emotions. For example, whereas more than 1,000 studies have addressed achievement-related anxiety to date, we were not able to locate more 
TABLE 1

Literature Search 1974-2000: Studies Linking Emotions to Learning and Achievement

\begin{tabular}{lrrl}
\hline Emotion & $1974-1990$ & $1991-2000$ & Research Tradition \\
\hline Joy & 32 & 29 & Mood research \\
Enthusiasm & 9 & 7 & Teacher enthusiasm \\
Hope & 0 & 9 & \\
Relief & 2 & 1 & \\
Pride & 17 & 10 & Achievement motivation \\
Gratitude & 2 & 1 & \\
Admiration & 0 & 0 & \\
Sadness & 10 & 5 & Mood research \\
Anger & 31 & 33 & Type A personality \\
Anxiety & 700 & 500 & Test anxiety \\
Hopelessness & 2 & 12 & Hopelessness theory \\
Shame and Guilt & 24 & 20 & Achievement motivation \\
Disappointment & 2 & 0 & \\
Boredom & 27 & 16 & Job monotony \\
Envy & 5 & 1 & \\
Contempt & 0 & 0 & \\
Surprise & 6 & 1 & Attributional theory \\
\hline
\end{tabular}

than 9 studies on the complementary emotion of students' hope. Also, there is a dearth of studies on students' regulation of their emotions (cf. Schutz \& Davis, 2000). Most studies were conducted from the perspective of specific traditions of research and addressed no more than one or two emotions, implying that a broader perspective on a range of emotions was largely lacking in much of the empirical research to date.

Theoretically, it may be assumed that students experience a rich diversity of emotions in academic settings. Academic learning and achievement are among the most important topics across the life span in our society today, especially because educational and professional careers, social relations, and the allocation of many kinds of resources are largely dependent on individual achievement. This implies that learning and achievement are singularly important and thus major sources of human emotions today, instigating a variety of self-referenced, task-related, and social emotions (cf. also Scherer, Wallbott, \& Summerfield, 1986). Furthermore, judging from the general functions of emotions for human agency, it may be assumed that emotions influence students' cognitive processes and performance, as well as their psychological and physical health.

In particular, this perspective is warranted for emotions that are directly linked to academic learning, classroom instruction, and achievement (e.g., enjoyment of learning, pride of success, or test-related anxiety). We propose to use the term academic emotions to denote such emotions. By defining academic emotions in this way, the term academic is used as is commonly done with terms such as academic motivation or academic self-concept. In doing so, the domain of academic emotions would include students' achievement emotions experienced in school or university settings, but goes beyond emotions relating to success and failure by also cov- ering, for example, emotions relating to instruction or to the process of studying (see Table 2).

The following research questions guided our studies on academic emotions:

1. Which emotions do students experience in academic settings when attending class, studying, and taking tests and exams? Furthermore, what are the elements of these emotional experiences and how are they structured?

2. How can we measure students' academic emotions?

3. How do these emotions affect learning, academic achievement, and students' health?

4. What are the origins of these emotions within students' personality and in their environments?

5. What can we do to foster positive academic emotions and to help students avoid negative emotions, or to cope with negative emotions in flexible ways once they emerge?

To date, our research has mainly addressed the first four of these questions, which may be regarded as basic and have to be answered before educational applications can be designed. In addressing these questions, we used qualitative as well as quantitative methods. The logic underlying our strategy implies that qualitative, exploratory analysis may be best suited to develop insights into the range and phenomenology of students' emotions and to generate hypotheses, whereas quantitative assessment is needed for the more precise analysis of effects and causes.

In the following, we give an overview of our research pertaining to these four questions. Specifically, in the sections of this article we address the following parts of our research in turn:

1. In a series of qualitative case studies, we explored the occurrence and phenomenological structures of academic emotions.

2. Based on our exploratory evidence, we developed a quantitative self-report instrument measuring nine academic

TABLE 2

The Domain of Academic Emotions: Examples

\begin{tabular}{lcc}
\hline & Positive & Negative \\
\hline $\begin{array}{l}\text { Task-related and self-related } \\
\text { Process } \\
\text { Prospective }\end{array}$ & Enjoyment & Boredom \\
& Anticipatory joy & Hopelessness \\
Retrospective & Hope & Anxiety \\
& Joy about success & Sadness \\
& Satisfaction & Disappointment \\
& Pride & Shame and guilt \\
Rocial & Relief & \\
& Gratitude & Anger \\
& Empathy & Jealousy and envy \\
& Admiration & Contempt \\
& Sympathy and love & Antipathy and hate \\
\hline
\end{tabular}


emotions experienced by students (the Academic Emotions Questionnaire [AEQ]).

3. In a number of quantitative studies using the AEQ, we tested assumptions underlying Pekrun's (1992b) cognitive-motivational model concerning the effects of emotions on students' self-regulated learning and achievement.

4. Finally, we developed and tested a social cognitive, control-value theory on the individual and social antecedents of academic emotions.

In conclusion, we emphasize the reciprocal nature of linkages between academic emotions, their effects, and their antecedents. Also, we discuss the need for strengthening the study of emotions in educational psychology, and the value of using multiple research strategies to analyze this domain of human affect.

\section{EXPLORING THE OCCURRENCE AND STRUCTURES OF ACADEMIC EMOTIONS: QUALITATIVE CASE STUDIES}

How do students feel at school and university, and what are the contents, sources, and functions of the emotions they experience? In a series of five exploratory studies, we analyzed the emotions of school and university students by means of qualitative interviews and questionnaires. We asked our participants about their emotional experiences in academic settings when in class, studying, and taking tests and exams. Also, we asked about the quality and the elements of these experiences and about their origins and consequences. In the first study, students were asked to recall typical academic episodes from their autobiographical memories and to report the emotions experienced within these episodes (Pekrun, 1992c). The other four studies used a more situated approach by interviewing participants immediately after classroom instruction, an exam, or a daily period of studying (cf. Spangler, Pekrun, Kramer, \& Hofmann, in press; Titz, 2001). As part of each study, we presented a fixed sequence of questions, but answers were less constrained, the focus being on individual descriptions of emotional episodes. In addition, in two of these studies assessing emotions during exams, video reconstruction procedures were used and physiological activation recordings were made (Spangler et al., in press).

\section{Frequencies of Different Emotions}

In accordance with theoretical expectations, the results of the five studies showed that students experience a wide range of emotions in academic settings. There was virtually no major human emotion not reported by our participants, disgust being the only notable exception. Emotional diversity implies that theory-driven approaches to students' emotions that limit the range of emotions considered for theoretical reasons may be in danger of missing important parts of students' affective life. For example, this may apply to test anxiety research and to traditional conceptions of hope, fear, pride, and shame as relating to achievement motivation.

Different categories of discrete emotions appeared with differing frequencies, depending in part on the type of academic situation addressed. Overall, anxiety was the one emotion reported most often, accounting for $15 \%$ to $25 \%$ of all emotions reported in our studies. Anxiety was mentioned most often not only in relation to taking exams, but also with reference to being in class or studying at home. Achievement pressure and expectancies of failure were reported as major contributors to emotional arousal, thus pointing to the need to enhance our students' psychological well-being by giving them chances to cope with excessive demands, and by increasing opportunities for success. However, despite the frequency of reports about anxiety, positive emotions were described about as often as negative emotions. Aside from anxiety, emotions reported most often were enjoyment of learning, hope, pride, and relief, as well as anger, boredom, and shame. In addition, there were accounts of several less frequently reported emotions (e.g., the social emotions of gratitude, admiration, contempt, and envy). Hopelessness was also reported less often, but some accounts of this emotion involved reports about personal tragedies including suicidal ideation relating to failing academic exams.

\section{Tracing Unexpected Phenomena}

The qualitative accounts given by our participants also enabled us to detect phenomena that otherwise would have gone unnoticed. A case in point was students' meta-emotions, that is, their feelings about their own emotions. For example, a number of students gave detailed accounts of experiencing anger about being anxious before exams. In some of these students, this anger helped them to find ways to cope with the anxiety, thus implying that meta-emotions may facilitate students' coping with negative emotions, something educators may wish to consider when trying to assist students in dealing with their affective experiences. An example pertaining to the sources of academic emotions is our participants' reports about academic boredom. We had expected that boredom should occur when demands are too low, as in the case of high-ability students who are taught in regular classes. Many of our participants' reports about boredom conformed to this analysis: When self-evaluations of abilities were high and instructional demands low, students reported that they felt bored and daydreamed. However, a sizable number of other students told us that they had experienced boredom when feeling unable to keep up with demands, implying that boredom was connected to low self-evaluations of abilities and high evaluations of demands. Apparently, boredom may serve functions of escaping behaviorally or mentally from sit- 
uations not providing sufficient stimulation, but may also serve as an escape from situations having demands that are beyond the student's capabilities.

\section{Constructing Taxonomies of the Internal Structures of Academic Emotions}

From a more systematic perspective, we used our exploratory findings as an empirical basis for constructing theoretical taxonomies of the internal structures of different academic emotions. Our participants reported a broad range of affective, cognitive, physiological, and motivational elements of their emotional experiences that were used for creating these taxonomies. For example, concerning cognitive components, three major categories of cognitions that were experienced as being part of academic emotions were thoughts about the task (e.g., the quantity, difficulty, and relevance of tasks), thoughts about mastery and achievement, and thoughts about the social situation within an academic setting.

Many of these cognitive components were reported as relating to more than one emotion. In a similar vein, some other types of components were also shared by several emotions (e.g., facets of perceived physiological arousal). This would suggest some overlap among different emotions, as in the case of worries about failure that were reported as being part of exam-related anxiety but also as components of shame and hopelessness. Rather than being characterized by specific, exclusive elements, it seems that different emotions show specific profiles of components, some of them being shared with other emotions. One general implication is that it may be difficult to measure different emotions in nonoverlapping ways, making it difficult to ensure discriminant validity of these measures. In this regard, contemporary test anxiety scales containing worry items (cf. Hodapp \& Benson, 1997; Sarason, 1984) may measure shame or hopelessness in addition to anxiety, thus making it necessary to reinterpret much of the empirical evidence gathered using them.

\section{Academic Emotions and Physiological Activation}

Finally, we also used our qualitative data to analyze relations between academic emotions and stress-related physiological processes. It is interesting that measures of emotional intensity based on our participants' qualitative reports about their emotions experienced during an important exam were systematically related to cortisol levels before and after the exam, whereas questionnaire-based measures showed a much less consistent pattern. Specifically, anxiety during an exam was positively related to postexam cortisol levels indicating physiological activation during the exam, whereas problem-focused as well as emotion-oriented coping during the exam were negatively related to cortisol levels, implying that coping had reduced physiological activation. This evidence suggests that qualitative reports may prove useful even for studying functional relations between subjective and physiological levels of emotions, a field that has been plagued by inconsistent findings to date (Spangler et al., in press).

In sum, findings of our qualitative studies demonstrated that students experience a rich and intense emotional life in academic settings, suggesting that reductionist conceptions of students' emotions may fall short of adequately covering this domain. Although anxiety was the single discrete emotion reported most often, positive emotions were reported no less often than negative emotions, thus pointing to the need to investigate them more thoroughly (cf. also Fredrickson, 2001). Furthermore, our findings allowed us to trace a number of unexpected phenomena as in the case of meta-emotions, and to build empirically based conceptual taxonomies of the internal structures of academic emotions.

\section{QUANTITATIVE MEASUREMENT: THE AEQ}

Whereas qualitative methods may be ideally suited to explore new fields, quantitative measures are needed for more rigorous tests of hypotheses. From its start in the 1950s, test anxiety research recognized the need for quantitative measurement applications. The progress of this field was tightly connected to advances in test anxiety measurement. Today, there are dozens of scales assessing this single emotion (cf. Hodapp \& Benson, 1997; Zeidner, 1998). Concerning academic emotions other than test anxiety, however, explicit measures are largely lacking as of yet. One exception is the anger measure presented by Smith, Furlong, Bates, and Laughlin (1998).

Previous research on academic emotions beyond anxiety used general measures of emotions not tailored to the academic domain or sets of single rating scales assessing various emotions following success and failure (cf. Weiner, 1985). Measures of general emotions, however, are removed from the academic domain and probably less predictive for academic achievement than more domain-specific scales. For example, general trait anxiety correlates less with students' achievement than their test anxiety (Hembree, 1988). Rating scales based on single items, on the other hand, may be economic and useful under specific experimental circumstances but may lack reliability and cannot adequately represent the detailed internal structures of academic emotions.

We therefore attempted to develop a multidimensional instrument that measures a number of more important academic emotions in domain-specific ways, using multiple items for each emotion to represent different components of these emotions. In doing so, we adopted the standards that have been set by recent advances in test anxiety measurement (Hodapp \& Benson, 1997). 
Theoretical Considerations Guiding Scale Development

A number of conceptual decisions had to be made at the outset. First, we needed a working definition of the concept of emotion. In line with contemporary component process models (e.g., Scherer, 1984), we view emotions as involving sets of interrelated psychological processes. Affective, cognitive, physiological, and motivational component processes may be the most important (e.g., feeling tense and uneasy, worrying, being activated physiologically, and wanting to escape in anxiety). Such a conception goes beyond traditional models of test anxiety by taking motivational components into account as well. Motivational components are not represented by recent test anxiety scales, although they have been included in items of early instruments such as the Test Anxiety Questionnaire (Mandler \& Sarason, 1952). Concerning the contents of the components of different emotions, we made use of the evidence-based taxonomies derived from our exploratory data.

Second, we decided to develop scales for a limited set of emotions that may be important in many academic situations and that can be assumed to affect students' learning, achievement, and health. Specifically, we used three criteria in creating this set of emotions: (a) The scales should represent those categories of primary human emotions that play a role in academic settings-According to our exploratory data, this is true of joy, anger, anxiety, and shame, as well as hopelessness, which may be regarded as an anticipatory version of the primary emotion of sadness; (b) we wanted to take those eight emotions into account, which were reported frequently by students in our exploratory studies (see the previous section); and finally, (c) with regard to emotion effects, we wanted to include positive and negative emotions, as well as both activating and deactivating emotions within these categories because the two dimensions of valence and activation may be regarded as basic determinants of many effects of emotions (see the next section). The resulting set of emotions contains the positive emotions of enjoyment, hope, and pride (positive activating emotions), as well as relief (positive deactivating), and the negative emotions of anger, anxiety, and shame (negative activating), as well as hopelessness and boredom (negative deactivating; see Table 3).

Third, clarification concerning the situational and temporal generality of the emotion constructs to be measured was necessary. Regarding academic situations, being in class, studying outside of class, and taking tests and exams are the three most important types of academic situations at school and university. These situations are characterized by different functions and social structures, implying that emotions relating to them may differ as well. For example, enjoyment of classroom instruction may be quite different from enjoying the challenge of an exam. We therefore decided to develop separate scales pertaining to class-related, learning-related, and test-related emotions. Concerning temporal generality,
TABLE 3

Academic Emotions Questionnaire: Reliability of the Trait Scales

\begin{tabular}{|c|c|c|c|c|c|c|}
\hline \multirow[b]{3}{*}{ Emotion } & \multicolumn{6}{|c|}{ Scales } \\
\hline & \multicolumn{2}{|c|}{$\begin{array}{c}\text { Learning-Related } \\
\text { Emotions }\end{array}$} & \multicolumn{2}{|c|}{$\begin{array}{l}\text { Class-Related } \\
\text { Emotions }\end{array}$} & \multicolumn{2}{|c|}{ Test Emotions } \\
\hline & $\alpha$ & Items & $\alpha$ & Items & $\alpha$ & Items \\
\hline Enjoyment & .90 & 14 & .89 & 15 & .90 & 23 \\
\hline Hope & .86 & 9 & .84 & 9 & .89 & 16 \\
\hline Pride & .84 & 9 & .86 & 9 & .92 & 16 \\
\hline Relief $^{a}$ & - & - & - & - & .89 & 14 \\
\hline Anger & .89 & 14 & .85 & 11 & .89 & 17 \\
\hline Anxiety & .92 & 18 & .89 & 13 & .94 & 31 \\
\hline Hopelessness & .93 & 13 & .88 & 10 & .94 & 21 \\
\hline Shame & .90 & 14 & .91 & 15 & .93 & 19 \\
\hline Boredom $^{\mathrm{b}}$ & .93 & 17 & .93 & 14 & - & - \\
\hline
\end{tabular}

${ }^{\mathrm{a}}$ Relief scale for test emotions only. ${ }^{\mathrm{b}}$ Boredom scale for learning-related and class-related emotions only.

we wanted to construct items so that they can be administered using different instructions, thus making it possible to measure trait academic emotions (e.g., trait test anxiety), course-related emotions pertaining to a specific course and class, as well as state academic emotions experienced within single episodes of academic life (e.g., state test anxiety). On a bipolar conceptual continuum representing emotional traits versus states, trait academic emotions would be located at the trait end of the continuum, state academic emotions at the state end, and course-related emotions in between.

\section{Construction of Scales}

Item construction was based on the student reports gained in our exploratory studies, on theoretical considerations, and, concerning test anxiety, on Sarason's (1984) Reactions-to-Tests Questionnaire and Hodapp and Benson's (1997) Integrative Test Anxiety Questionnaire. From an initial item pool, items were selected for preliminary versions of the scales by using expert judgment and criteria of redundancy. Selection of items for the final versions was based on item statistics of the preliminary versions and on results of confirmatory factor analysis for each scale (cf. Titz, 2001).

\section{Item Statistics, Reliabilities, and} Structures of Scales

Table 3 presents item numbers and internal reliabilities for the trait versions of the AEQ scales. Reliabilities are based on two samples of university students (learning-related and class-related emotion scales: $N=230$; test emotion scales: $N=222$ ). Coefficients imply that internal reliabilities are quite satisfactory.

Confirmatory factor analysis showed that internal structures of trait academic emotions can differ between emotions. Specifically, whereas items relating to affective, 
cognitive, physiological, and motivational components separated in some scales (e.g., in the test anxiety scale), they showed less differentiation in others (e.g., in the boredom and hopelessness scales). Future research should address the precise nature of these structural differences. Learning-related and class-related emotions correlated moderately with their respective counterparts relating to tests (average $r=.58$ ), whereas correlations of learning-related versus class-related emotions were somewhat higher (average $r=.64$ ).

Concerning interrelations of different emotions within these groups, four clusters of emotions emerged: (a) enjoyment, hope, and pride; (b) relief; (c) anxiety, shame, and hopelessness; and (d) anger and boredom. These clusters suggest that academic emotions can be grouped according to their antecedents. The first cluster represents emotions that are induced by positive events, whereas relief is a positive emotion that is induced when a negative process is stopped. The third cluster represents negative emotions implying lack of subjective control and the last cluster negative emotions characterized by higher levels of control (cf. Roseman, Antoniou, \& Jose, 1996). Correlations between these clusters were low to moderate, whereas within-cluster correlations were higher, although well below the respective reliabilities in each case. An exception was the high correlations between anxiety and hopelessness $(r>.70)$. Because anxiety and hopelessness may differentially relate to outcomes (see following), we nevertheless decided to keep these scales separate. Overall, this pattern of scale interrelations seems to be in line with hierarchical models of dimensions of human affect (cf. Watson \& Clark, 1992).

In addition to the long versions of the AEQ scales, shorter eight-item versions are available as well. Also, the scales have been administered under alternative instructions pertaining to single courses and to transient emotional states. Reliabilities were equivalent to those of the trait versions (average reliabilities of the scales of the short trait versions, the course-related versions, and the state versions were $=.87$, .86 , and .87 , respectively; cf. Titz, 2001). Also, we recently developed a version of the instrument pertaining to school students' emotions experienced in different academic domains at school (e.g., in mathematics). Finally, we translated the scales (short versions) into the English language and analyzed these versions using samples of undergraduate students at a midwestern Canadian university. Results imply equivalence of reliability and validity of the English-language versions (average scale reliability was $=.86$; Goetz, Pekrun, Perry, \& Hladkyj, 2001).

\section{THE IMPACT OF ACADEMIC EMOTIONS ON SELF-REGULATED LEARNING AND ACHIEVEMENT: TESTING ASSUMPTIONS OF A COGNITIVE-MOTIVATIONAL MODEL}

Do students' emotions influence their academic learning, self-regulation, and achievement? Does it matter, for exam- ple, if a student is bored and indulges in daydreaming while in class, or feels excited and enjoys the lesson?; if the student hopes for success when taking an exam or is afraid of failing it? Everyday experiences, as well as psychological theorizing, tell us that the answer should be yes: Emotions serve the functions of preparing and sustaining reactions to important events and states by providing motivational and physiological energy, by focusing attention and modulating thinking, and by triggering action-related wishes and intentions. This would imply that emotions can profoundly affect students' thoughts, motivation, and action. However, empirical evidence is limited to date. We used findings from experimental mood studies and test anxiety research to deduce hypotheses on the impact of academic emotions. We then tested parts of these hypotheses in a series of cross-sectional, longitudinal, and diary studies using the AEQ.

\section{Previous Research}

Laboratory-based experimental research on mood effects has shown that mood, which may be regarded as low-intensity emotion, can have a number of distinct effects on cognitive processes and performance. One well-known result is that positive and negative mood can enhance mood-congruent memory processes by mechanisms of state-dependent learning and mood-congruent recall (e.g., Levine \& Burgess, 1997). Second, positive and negative mood have been shown to trigger specific modes of thinking and problem solving. Positive mood may facilitate holistic, intuitive, and creative ways of solving problems, as well as an optimistic reliance on generalized knowledge structures (e.g., Bless et al., 1996). In contrast, negative mood may enhance more focused, detail-oriented, analytical, and algorithmic modes of processing information. Finally, it has been shown that mood may produce task-irrelevant thinking that may be detrimental for task performance (cf. Ellis \& Ashbrook, 1988; Meinhardt \& Pekrun, in press).

However, many of these and other specific effects found in experimental research have been weak and inconsistent, and it is open to question as to what extent they are generalizable to field settings outside the laboratory. For some phenomena, it may reasonably be assumed that generalizability is limited. A case in point is emotion effects on cognitive resources (see following). Because laboratory research on human emotions is confined by methodological and ethical constraints, it may well be suited to generate hypotheses, but it cannot replace a more direct analysis of the emotions experienced by students in real-life educational settings.

Thus far, field research of this kind has focused on students' test anxiety. This research has shown that test anxiety can reduce working memory resources, leading to an impairment of performance at complex or difficult tasks that draw on these resources. Consequently, test anxiety tends to correlate negatively with academic achievement at school and uni- 
versity (cf. Hembree, 1988; Zeidner, 1998). These are cumulative, consistent findings, but beyond test anxiety, evidence on the impact of academic emotions is scarce (with few notable exceptions; cf. Boekaerts, 1993; J. E. Turner \& Schallert, 2001).

\section{A Cognitive-Motivational Model on the Effects of Emotions}

In a cognitive-motivational model (Pekrun, 1992c), it is assumed that the effects of emotions on learning and achievement are mediated by a number of cognitive and motivational mechanisms. Of primary importance should be mediation by students' motivation to learn, strategies of learning, cognitive resources, and self-regulation of learning.

Different emotions can influence these mechanisms in different ways. To reduce conceptual complexity, experimental mood research on performance effects of emotions has traditionally focused on differences related to the valence dimension of emotions (positive vs. negative mood). In our cognitive-motivational model, it is assumed that a second traditional dimension of emotions is no less important, namely activation. Using these two dimensions, four groups of emotions in general, and of academic emotions in particular, may be distinguished with reference to their performance effects: positive activating emotions (such as enjoyment of learning, hope for success, or pride); positive deactivating emotions (e.g., relief, relaxation after success, contentment); negative activating emotions (such as anger, anxiety, and shame); and negative deactivating emotions (e.g., boredom, hopelessness). Note, however, that using these two dimensions instead of one still requires a number of simplifications. For example, anxiety may lead to behavioral freezing instead of activation under specific circumstances, and there may be variants of boredom that are quite arousing. In line with the findings of mood and test anxiety research, the model assumes that mediating mechanisms and resulting academic achievement are influenced by these four categories of emotions as follows.

Motivation. Emotions may trigger, sustain, or reduce academic motivation and related volitional processes. They can do so by inducing emotion-specific goals and intentions, which may be facilitated by emotion-congruent ways of processing self-related and task-related information. For example, attention and recall can be focused on positive self-efficacy information in a positive mood and on negative information in a negative mood (cf. Olafson \& Ferraro, 2001). In this way, positive activating emotions such as enjoyment of learning may generally enhance academic motivation, whereas negative deactivating emotions may just be detrimental (e.g., hopelessness, boredom).
The other two categories of emotions, however, may show more complex effects. Positive emotions such as relief or relaxation can deactivate any immediate motivation to continue academic work, thus facilitating disengagement. However, being positive emotions, they can also serve as reinforcers strengthening motivation for the next stage of learning. The effects of negative activating emotions may be even more ambivalent. Anger, anxiety, and shame can be assumed to reduce intrinsic motivation, because negative emotions tend to be incompatible with enjoyment as implied by interest and intrinsic motivation. On the other hand, it follows from their activating nature that these emotions can induce strong motivation to cope with the negative events that caused them, thus strengthening specific kinds of extrinsic motivation. For example, task-related anger may be assumed to trigger motivation to overcome obstacles (cf. also Bandura \& Cervone, 1983), and anxiety and shame may induce motivation to avoid failures by investing effort, thus strengthening academic motivation. Recent findings by J. E. Turner and Schallert (2001) on students' shame are in line with this assumption, as well as earlier research by Weiner (1985).

Strategies for learning. Extrapolating from the aforementioned research on mood and problem solving, it may be assumed that positive academic emotions facilitate the use of flexible, creative learning strategies such as elaboration, organization, critical evaluation, and metacognitive monitoring. Negative emotions, on the other hand, may trigger the use of more rigid strategies, such as simple rehearsal and reliance on algorithmic procedures. These effects should be stronger in activating than in deactivating emotions. Emotions such as relaxation or boredom imply physiological as well as cognitive deactivation, thus leading to reduced attention and more shallow, superficial processing of information.

Cognitive resources. Emotions serve functions of directing attention toward the object of emotion, implying that they use cognitive resources and can distract attention away from tasks. This has traditionally been assumed for negative emotions (cf. Ellis \& Ashbrook, 1988; Zeidner, 1998), but has been demonstrated experimentally for positive emotions as well (Meinhardt \& Pekrun, in press). Emotions such as enjoyment, pride, admiration, anxiety, anger, or envy can relate to the setting, other persons, or the self, thus producing task-irrelevant thinking, reducing cognitive resources available for task purposes, and impairing academic achievement.

However, it would be misleading to infer from experimental research that this should hold true for all kinds of academic emotions. In emotions directly relating to the process of learning and task performance, the situation may be different. Specifically, enjoyment of dealing with learning material and related experiences of flow may direct attention toward the task at hand, thus allowing for the full use of cognitive re- 
sources instead of reducing them. The terms intrinsic and extrinsic can be borrowed from motivation research to characterize the implied distinction. Seen from a task perspective, emotions relating to the setting, other persons, or the self can be considered extrinsic emotions. Emotions such as task-related enjoyment, on the other hand, are intrinsic emotions to the extent that they relate to inherent properties of task material or the process of dealing with such material (Pekrun, 1998). Positive intrinsic emotions may be assumed to direct attention toward the task, thus directly facilitating learning and performance.

Self-regulation versus external regulation of learning. Self-regulation of learning implies planning, monitoring, and evaluating one's own learning in flexible ways and, in doing so, adapting learning strategies to task demands and the progress made. Because self-regulated learning presupposes cognitive flexibility, it may be speculated that it is facilitated by positive emotions. Negative emotions, on the other hand, may be assumed to motivate students to rely on external guidance.

Academic achievement. Emotion effects on students' achievement may depend on the interplay between these different motivational and cognitive mechanisms of self-regulation and on interactions between these mechanisms and task demands. This implies that emotion effects on academic achievement will inevitably be complex and overdetermined. Nevertheless, a number of general assumptions can be deduced from the preceding hypotheses.

Generally, positive activating emotions may be assumed to affect achievement positively by strengthening motivation and enhancing flexible learning. Specifically, this may be true for intrinsic positive emotions such as task enjoyment, which provide the additional advantage of directing attention toward the task. In contrast, negative deactivating emotions (e.g., boredom, hopelessness) may generally be detrimental because they erode motivation, direct attention away from the task and make any processing of task-related information shallow and superficial.

The effects of positive deactivating as well as negative activating emotions, on the other hand, may be equivocal. Posi- tive deactivating emotions may be detrimental for immediate performance, but may be beneficial by reinforcing long-term motivation to invest effort. Negative activating emotions such as anger and anxiety may impair achievement by reducing intrinsic motivation and producing task-irrelevant thinking, but they may also benefit achievement by strengthening extrinsic motivation. Specifically, such beneficial effects may occur when positive overall expectancies are held, and when learning does not require too much cognitive flexibility, but can draw on rehearsal strategies and algorithmic procedures instead. This ambivalence could well explain why correlations between test anxiety and academic achievement have often been weak and rarely explain more than $10 \%$ of the variance in achievement scores (Hembree, 1988; Ma, 1999).

\section{Empirical Findings}

In a series of seven cross-sectional, three longitudinal, and one diary-based study using samples of university and school students, we analyzed the relations of academic emotions to learning and achievement (summarized in Pekrun, Hochstadt, \& Kramer, 1996; Pekrun \& Hofmann, 1999; Pekrun, Molfenter, Titz, \& Perry, 2000; Titz, 2001). In these studies, we used trait or state versions of our AEQ scales to measure students' academic emotions. Additionally, German versions of the Study Interest Scale (Winteler, Schiefele, Krapp, \& Wild, 1991) were used for assessing students' academic interest; trait and state versions of a German adaptation of the Motivated Strategies for Learning Questionnaire (Winteler et al., 1991; based on Pintrich, Smith, Garcia, \& McKeachie, 1993) to measure learning strategies and effort; scales assessing task-irrelevant thinking when learning and taking tests as (negative) indicators of the availability of cognitive resources (adapted from Sarason, 1984); and grades as well as performance on written exams as indicators of academic achievement (Perry, Hladkyj, Pekrun, \& Pelletier, 2001).

Our findings indicated that academic emotions related in significant ways to variables of students' learning and achievement. These relations proved to be rather similar for university and secondary school students and for trait and state measures of emotions and learning. Table 4 shows exemplary correlations between major trait learning-related

TABLE 4

Learning-Related Emotions: Exemplary Linkages to Components of Self-Regulated Learning

\begin{tabular}{|c|c|c|c|c|c|c|c|}
\hline \multirow[b]{2}{*}{ Emotion } & \multicolumn{2}{|c|}{ Motivation } & \multicolumn{2}{|c|}{ Strategies } & \multirow{2}{*}{$\frac{\text { Resources }}{\text { Irrelevant Thinking }}$} & \multicolumn{2}{|c|}{ Regulation } \\
\hline & Study Interest & Effort & Elaboration & Rehearsal & & Self-Regulated & External \\
\hline Enjoyment & $.62 * * *$ & $.43 * * *$ & $.44 * * *$ & .04 & $-.38 * * *$ & $.43 * * *$ & -.08 \\
\hline Hope & $.44 * * *$ & $.49 * * *$ & $.33 * * *$ & .13 & $-.40 * * *$ & $.46^{* * *}$ & -.07 \\
\hline Anger & $-.42 * * *$ & $-.26^{* * *}$ & $-.21 * *$ & .05 & $.41 * * *$ & -.13 & $.27 * * *$ \\
\hline Anxiety & $-.21 * *$ & $-.19 * *$ & $-.22 * * *$ & .12 & $.45^{* * *}$ & $-.26^{* * *}$ & $.27 * * *$ \\
\hline Boredom & $-.63 * * *$ & $-.50 * * *$ & $-.26 * * *$ & -.06 & $.72 * * *$ & $-.21 * *$ & $.17 *$ \\
\hline
\end{tabular}

Note. $N=230$ university students

$* p<.05 . * * p<.01 . * * * p<.001$ 
emotions and components of self-regulated learning in a sample of 230 university students (Titz, 2001, Study 2).

Motivation and effort. In consistent ways, enjoyment, hope, and pride correlated positively with students' interest, intrinsic motivation (i.e., motivation to learn because the material is interesting and learning is enjoyable), extrinsic motivation (motivation to learn to attain outcomes), total motivation to learn, and self-reported academic effort (see Table 4). For test-related relief, correlations were less consistent and close to zero. This is in line with assumptions on the deactivating effects of emotions such as relief and relaxation. Alternatively, relations of relief to learning may be epiphenomena of relations between test anxiety and learning because relief is a tension-reducing emotion that tends to be tied closely to preceding anxiety (relief correlated positively with test anxiety).

In contrast, the negative deactivating emotions of boredom and hopelessness correlated negatively with all of these motivational variables and with self-reported effort (cf. Table 4), thus suggesting that these two emotions may be detrimental for students' academic motivation. Concerning the activating emotions of anger, anxiety, and shame, average correlations were negative as well. However, correlations for these emotions were lower, and in some of our studies, the coefficients for anxiety and self-reported academic effort were essentially zero (cf. Pekrun \& Hofmann, 1999). In line with theoretical expectations, ambivalent relations to intrinsic versus extrinsic motivation proved to be one possible reason. For example, it turned out that students' anxiety correlated negatively with intrinsic as well as overall extrinsic motivation but positively with extrinsic avoidance motivation (i.e., motivation to invest effort to avoid failures; Pekrun \& Hofmann, 1999).

Learning strategies. With the exception of relief, positive emotions related positively to metacognitive strategies, elaboration, organization, and critical thinking, thus suggesting that positive academic emotions may in fact facilitate flexible, creative modes of thinking. An alternative interpretation would be that creative learning is more enjoyable. Relations between negative emotions and flexible learning strategies were negative but weaker and less consistent.

Concerning more rigid ways of learning, most of the correlations with rehearsal strategies were near zero for both positive and negative emotions (cf. Table 4). However, in some of our data sets, we found significant positive correlations between anger, anxiety, and shame on one hand and use of rehearsal strategies on the other. In line with expectations, these correlations suggest that negative activating emotions may well facilitate the use of specific kinds of learning strategies, even if such effects do not appear in more consistent ways when self-report measures of learning strategies are used.
Cognitive resources. Relations between positive emotions and task-irrelevant thinking were consistently negative (for examples, see Table 4), relief again being an exception. Somewhat contrary to expectations, correlations were negative not only for intrinsic, task-related enjoyment, but for the extrinsic emotions of hope and pride as well (Titz, 2001), perhaps indicating that beneficial motivational effects of these emotions on attention can override the effects of any task-irrelevant thoughts implied by them. Negative emotions, on the other hand, correlated positively with task-irrelevant thinking. In test anxiety research, irrelevant thinking has often been defined as a component of this specific emotion (cf. Hodapp \& Benson, 1997). The findings of our studies suggest that relations of other negative emotions to irrelevant thinking are at least equally strong. One important case in point is boredom because mental withdrawal and daydreaming are strongly related to this emotion.

Perceived self-regulation versus external regulation. Beyond single component processes of self-regulation, how do students' academic emotions relate to their overall sense of self-regulation, as compared to being controlled by others? We used two scales developed for the purposes of this research to measure students' perceptions of the source of their learning-related regulation (Titz, 2001). These scales pertain to students' self-regulation versus external regulation by others concerning the goals of learning, the material used, the learning strategies employed, and the monitoring and evaluation of outcomes. There were significantly positive correlations between positive academic emotions and perceived self-regulation and between negative academic emotions and perceived external regulation (see Table 4). These findings suggest that positive emotions foster students' self-regulation, whereas negative emotions lead to reliance on external guidance. However, the reverse direction of causation may play a role here as well: Self-regulating one's own learning may induce positive feelings, whereas external control may induce anger, anxiety, or boredom.

Academic achievement. Academic emotions related significantly to students' academic achievement in a variety of ways (cf. Pekrun et al., 1996; Pekrun \& Hofmann, 1999; Titz, 2001). Moving beyond cross-sectional correlations, university students' emotions measured early in the semester predicted cumulative grades as well as final course exam scores at the end of the semester (Pekrun et al., 2000). With the exception of relief, positive emotions such as academic enjoyment, hope, and pride predicted high achievement, and negative emotions predicted low achievement. Concerning negative emotions, average coefficients were higher for the deactivating emotions of hopelessness and boredom than for the activating emotions of anxiety, anger, and shame, which is in line with assumptions on ambivalent effects of activating 
negative emotions. Specifically, test anxiety proved to relate less closely to achievement than hopelessness and boredom, indicating once again that test anxiety is not necessarily the most detrimental negative academic emotion.

Finally, apart from achievement per se, negative academic emotions longitudinally predicted students' withdrawal from university courses (Ruthig, Hladkyi, Hall, Pekrun, \& Perry, 2002) and were significantly more elevated in students who dropped out of university compared to students who finished their studies (Ziegler, 2001).

In sum, findings corroborate that students' academic emotions are closely linked to their learning, self-regulation, and scholastic achievement. However, concerning causal interpretations of this evidence, two caveats are in order. First, even predictive, longitudinal evidence does not imply that effects of emotions on learning and performance represent the only relevant direction of causation. Rather, it may be assumed that emotions, learning, and achievement are linked by reciprocal causation, with students' emotions influencing achievement, but feedback of achievement in turn affecting their emotions (see section on reciprocal linkages).

Second, on a more general level, it cannot be inferred from the sample statistics normally derived from correlational and experimental studies that the implied relations between variables do in fact apply to all participants under study (cf. Schmitz \& Skinner, 1993). Our cross-sectional and longitudinal studies are no exception in this regard. To test generalizability, we used data from our diary study (Pekrun \& Hofmann, 1999) on exam-related emotions to conduct idiographic analyses by calculating intraindividual correlations within individual students over time $(N=72$ students, daily measurements over 6 weeks before and during final university exams). One main result was that for many emotions, synchronous and time-lagged relations with variables of learning were similar for all individuals in the sample and equivalent to the respective interindividual correlations, thus implying functional homogeneity across persons. For some relations, however, a different picture emerged. Specifically, it turned out that daily anxiety related differently to variables of learning in different students. For example, whereas anxiety correlated negatively with motivation to learn for some students, it correlated positively with motivation for others (see Figure 1). One reason for this heterogeneity of anxiety-motivation relations may be that anxiety effects on intrinsic versus extrinsic motivation tend to be balanced differently within different individuals: Some students may even profit motivationally from their anxieties, whereas others are handicapped.

The results of this study thus imply that it should prove fruitful to complement sample-based analyses of students' emotions and learning by idiographic analysis to test the generalizability of sample statistics to individuals. Preferably, not to trade off idiographic validity at the expense of nomothetic generalizability across individuals, this should be done by using combined idiographic-nomothetic strategies (cf. Schmitz \& Skinner, 1993).

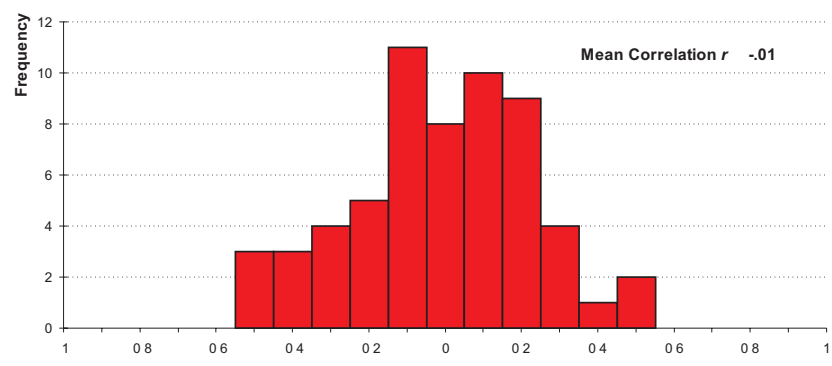

FIGURE 1 Anxiety and motivation to learn: distribution of intraindividual correlations.

\section{SOURCES OF ACADEMIC EMOTIONS: A SOCIAL COGNITIVE, CONTROL-VALUE THEORY}

Genetic dispositions, physiological processes, and cognitive appraisals can be regarded as main proximal sources of emotions. Because academic emotions are domain-specific variants of emotions in general, this should be true for this class of emotions as well. However, genetic dispositions and physiological processes of students are beyond the control of educators. In contrast, emotionally relevant appraisals of students may be shaped by their instructional and social environments, implying that research on appraisals and their environmental antecedents may help in designing measures of prevention, therapy, and optimization.

Test anxiety research, attributional studies, and recent investigations of students' hopelessness, anger, and negative affect have corroborated the importance of cognitive antecedents. Specifically, it has been shown that negative self-concepts and achievement-related expectancies, as well as a helpless attributional style, may be important for test anxiety and students' hopelessness (Abela \& Seligman, 2000; Hembree, 1988). Students' anger, on the other hand, may be characterized by task frustration combined with higher levels of subjective control, as well as high values of outperforming others (high need to win; Rhodewalt \& Morf, 1998). Negative affect after failure has been shown to be related to ability goals (J. C. Turner, Thorpe, \& Meyer, 1998). Concerning students' positive emotions, however, evidence on antecedents is largely lacking, with the exception of attributional studies showing that internal attributions of success may be important for positive achievement-related emotions (Weiner, 1985) and other person-directed emotions (Weiner, 1995).

\section{Individual Antecedents of Academic Emotions}

Causal attributions and causal expectancies may be regarded as specific cases of appraisals of subjective control and aca- 
demic self-concepts as appraisals of one's own competences underlying control. In a control-value theory of academic emotions (Pekrun, 1998, 2000), an attempt was made to integrate assumptions of expectancy-value and attributional theories of achievement-related emotions (Pekrun, 1992a; J. E. Turner \& Schallert, 2001; Weiner, 1985). The theory holds that control-related and value-related appraisals are main sources of students' academic emotions. Dependent on the time perspective of interest (retrospective, concurrent, or prospective), control cognitions may take forms of retrospective causal attributions, state-related control cognitions referring to the present situation, or future-related causal expectancies (cf. also Roseman et al., 1996). Major categories of causal expectancies are self-efficacy, situation outcome, and action-outcome expectations implying appraisals of causal agency and of probabilities of future events. In addition, intrinsic and extrinsic values and goals relating to academic learning and its outcomes are assumed to be important, interacting with control in such ways that, for most academic emotions, both control and values are necessary antecedents.

For example, it is assumed that learning-related enjoyment presupposes that the student has a sense of being able to master the material (high control) and intrinsically values the material (high interest). Anxiety is assumed to be triggered when expectations imply possible failure, on condition that achievement goals are of some subjective value (intrinsically relating to failures themselves or extrinsically to their consequences).

In our cross-sectional and longitudinal studies on academic emotions cited previously, we found that academic self-efficacy, academic control of achievement, and subjective values of learning and achievement related significantly to students' academic emotions (cf. Pekrun, 1998, 2000). Beyond synchronous relations, control also predicted emotions in longitudinal analysis (cf. Perry, Hladkyj, Pekrun, \& Clifton, 2001; Perry, Hladkyj, Pekrun, \& Pelletier, 2001). Furthermore, in a study on students' emotions relating to statistics courses (Barrera, 2001), we systematically tested the extent to which interactions of control and value variables may explain academic emotions. Scales of the AEQ were used to measure emotions, after the instruction had been tailored to the domain of statistics. A number of significant interactions emerged. For example, enjoyment originating from statistics was high when both statistics-related control and the subjective value of this domain were high, and low when either control or value, or both, were low. In contrast, anxiety emanating from statistics was characterized by a pattern of low control, combined with high value.

\section{Classroom Instruction, Social \\ Environments, and Academic Emotions}

In addition to individual sources of emotions, assumptions concerning the instructional and social antecedents of aca- demic emotions may be deduced from our model. Specifically, in line with social cognitive perspectives on human development, the model assumes that environmental factors of specific importance are those that influence students' control- and value-related appraisals initially, implying that subjective control and values mediate the impact of specific settings. In particular, this is assumed for the following groups of variables: (a) quality dimensions of classroom instruction (as exemplified by teacher enthusiasm inducing intrinsic values by means of emotional contagion; cf. Hatfield, Cacioppo, \& Rapson, 1994); (b) autonomy support versus control of students' learning (cf. also Patrick, Skinner, \& Connell, 1993); (c) achievement expectancies and values conveyed to the student by significant others, by educational goal structures, and by classroom interaction structures (e.g., competition vs. cooperation); (d) feedback and consequences of achievement (such as educational and occupational career outcomes); and (e) social relatedness and support in academic interactions (e.g., affiliation within the classroom; teachers' and parents' support after failure).

In line with these assumptions, test anxiety studies have shown that high achievement expectancies, pressure for achievement, classroom competition, feedback of failure, and punishment after failure correlate with students' achievement-related anxiety. Again, evidence beyond test anxiety is scarce. In our field studies, we found that teacher enthusiasm; achievement pressure; competition versus cooperation; feedback of achievement; and social reactions to achievement by teachers, parents, and peers, as well as competition, cooperation, and affiliation within the classroom significantly related to secondary school and university students' enjoyment of learning and hope for success, as well as to their anger, anxiety, hopelessness, and boredom (including cross-sectional correlations and longitudinal prediction; e.g., Pekrun, 1998, 2000; Pekrun et al., 2000). However, we have not yet tested the mediational assumptions implied by control-value theory in more direct ways.

\section{Implications for Instruction and Intervention}

Finally, a number of implications for prevention and therapy and for the design of instruction and educational environments may be inferred from our theoretical perspective. Individual prevention and therapy can aim at changing students' control and value appraisals underlying their emotions. For example, research done by Perry and his colleagues has shown that attributional retraining procedures can help students enhance their subjective control over academic performance (cf. Perry, Hechter, Menec, \& Weinberg, 1993; Perry $\&$ Penner, 1990). Concerning the design of instructional environments, some general guidelines that can be inferred from the theory are to (a) improve the quality of academic instruction; (b) give students autonomy, but only to the extent that they are able to self-regulate their learning; (c) convey high 
values of academic mastery, but adjust social expectations for achievement so that they match students' capabilities; (d) increase opportunities for success by using individual and cooperative reference norms for giving feedback and by inducing a culture of learning from errors; and (e) create flexible interaction structures that foster affiliation, cooperation, and support without denying the role of competition among peers (Pekrun, 1998; Perry, Schonwetter, Magnusson, \& Struthers, 1994; see also Astleitner, 2000; Covington, 1992). Educational intervention studies should consider exploring the empirical fruitfulness of strategies of this kind.

\section{RECIPROCAL LINKAGES BETWEEN EMOTIONS, EFFECTS, AND ANTECEDENTS}

The research perspectives discussed in the previous two sections pertain to the effects of emotions and to their antecedents. Specifically, our cognitive-motivational model addresses the impact of academic emotions on students' learning and achievement, and control-value theory their individual and social origins. Taken individually, the assumptions of the two models seem to suggest unidirectional causation: Environments and appraisals induce emotions, emotions in turn influence learning and achievement. Taken together, however, the assumptions of the two models imply that antecedents, emotions, and effects are linked by reciprocal causation (for a summary, see Figure 2).

Reciprocal causation in academic emotions may take similar forms as in other kinds of human affect (e.g., Lazarus \& Folkman, 1987). Two reciprocal linkages may be of specific importance. First, emotions affect students' achievement, but feedback of achievement and related experiences of success and failure can in turn influence students' emotions and may in fact be a major source of human affective development today. Reciprocal linkages of emotions and achievement may be characteristic both of short-term causation from one exam

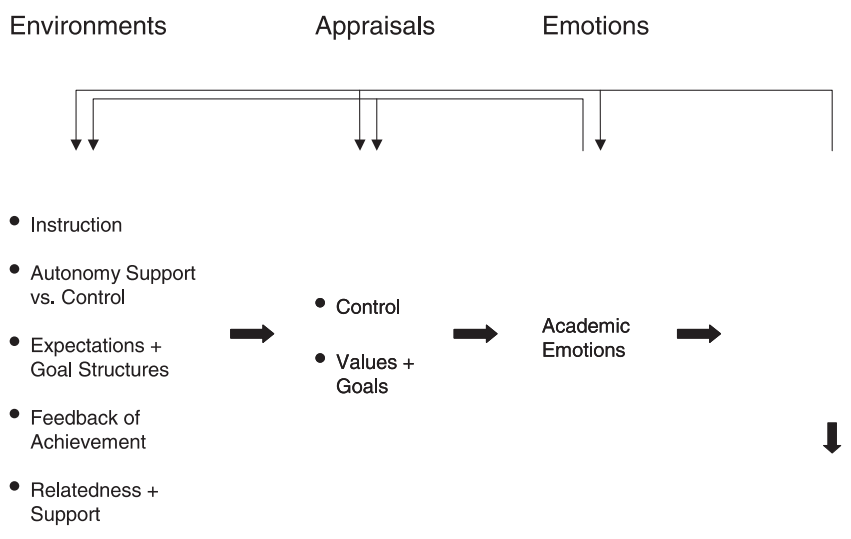

FIGURE 2 Summary of linkages between academic emotions, effects, and antecedents. to the next and of long-term affective development over the life span. Second, classroom instruction and social environments can induce academic emotions in students, but students' emotions can influence instruction, environments, and the behavior of significant others. For example, through the process of emotional contagion, a teacher's enthusiasm may stimulate excitement and positive affect in students, but having enthusiastic students in one's class may in turn fuel the teachers's enthusiasm in teaching this class.

Theoretically, such reciprocal linkages may take different forms, including both positive and negative feedback loops. For example, positive loops of emotions and achievement would imply that the levels of emotions and of achievement could increase or decrease over time in parallel ways, which might also be one of the reasons why the gap between highand low-achieving students tends to widen throughout the school years (e.g., Weinert \& Helmke, 1997). Negative feedback loops may help explain findings on academic emotions that seem paradoxical at first sight. For example, contrary to theoretical expectations, correlations between parents' and teachers' support on one hand and test anxiety on the other have been found to be near zero in a number of studies (cf. Hembree, 1988). This may well be due to negative feedback loops implying that support alleviates students' anxiety (negative effect of support on the level of anxiety) but is initially triggered by students' expression of anxiety (positive effect of anxiety on support).

Empirical evidence on reciprocal linkages of academic emotions is scarce. In our own longitudinal research, we found that test anxiety and academic achievement were linked by reciprocal causation (positive feedback loops) throughout the school years from Grades 5 to 10 (Pekrun, 1991, 1992a). Achievement had negative effects on anxiety over time, which were mediated by students' expectancies of failure. Anxiety in turn exerted negative effects on achievement. In similar ways, Meece, Wigfield, and Eccles (1990) and Schnabel (1998) have used longitudinal data to disentangle causal relations between test anxiety and students' academic achievement. For academic emotions other than test anxiety, however, evidence is largely lacking. Future research should address reciprocal causation by including measures of academic emotions into longitudinal classroom research.

\section{CONCLUSION}

The findings presented in this article demonstrate that students' academic emotions are often multifaceted, can be measured in reliable ways by the AEQ self-report scales, and relate significantly to students' learning, self-regulation, achievement, personality antecedents, and instructional as well as social environments. However, limitations of the studies summarized here should be noted as well. Specifically, the quantitative field studies we have conducted so far largely used cross-sectional or predictive designs, as yet 
not allowing more precise inferences of causal relations. In addition, the assessment of students' self-regulated learning, and of variables of appraisals and social environments, has focused on self-report scales in our studies to date. Bearing these limitations in mind, the findings may nevertheless warrant some more general conclusions and implications for future research.

\section{Strategies of Research}

Concerning strategies of analyzing students' emotions, the results of our research suggest that it can prove useful not to rely solely on qualitative or quantitative strategies alone, but rather to combine them in ways in which the relative advantages of both approaches are used. Starting with qualitative, exploratory analysis can help in appreciating the complexity of real-life affective experience, and thus lay the groundwork for constructing measures and undertaking quantitative studies. Furthermore, the findings of our diary study suggest that it may be useful to complement studies using sample-based designs with idiographic analysis, thus testing the generalizability of findings and ensuring that conclusions are valid for individual students' affective life, rather than remaining artifacts of sample statistics.

\section{Emotions and Students' Self-Regulation at Learning and Achievement}

Emotions seem to be closely intertwined with essential components of students' self-regulated learning such as interest, motivation, strategies of learning, and internal versus external control of regulation. Also, they predict students' academic achievement. Gaining a realistic account of students' competences for self-regulation and academic performance may require taking their emotions into account. In so doing, simplistic conceptions of negative emotions as bad and positive emotions as being good should be avoided because positive emotions are sometimes detrimental and negative emotions such as anxiety and shame beneficial. Furthermore, beyond the evidence discussed in this article, the role of emotion regulation for students' self-regulation of learning needs to be addressed more thoroughly (Schutz \& Davis, 2000).

\section{Sources of Emotions and the Design of Educational Environments}

Findings imply that academic emotions are closely tied to students' self-appraisals of competence and control in the academic domain, to the values and goals they attach to learning and achievement, and to classroom instruction and social environments affecting control, values, and goals. Implications for prevention, therapy, and an emotion-oriented design of educational environments can be deduced from the importance of these appraisals.

\section{Affective Educational Psychology: Acknowledging Emotional Diversity}

The findings of our studies imply that students experience a great variety of self-referenced, task-related, and social emotions in academic settings. Judging from the results of our qualitative case studies, positive emotions such as enjoyment of learning, hope, pride, admiration, or empathy appear to be no less representative of this diversity than negative emotions. To date, research on students' affective life has focused on test anxiety and has generally been biased toward negative emotions. To obtain a more complete picture of students' academic reality, it would seem necessary to analyze their positive experiences as well (cf. also Fredrickson, 2001). Such an analysis may be of specific importance for designing educational environments in such ways that they foster students' psychological well-being and learning beyond perspectives of preventing and modifying negative emotions. Going beyond test anxiety, which has been studied so extensively, the study of affect in educational psychology should thus address the full range of students' affective experiences, negative as well as positive. In so doing, it might profit anew from taking up broader perspectives on emotional diversity as implied, for example, by Weiner's (1985) attributional theory of achievement emotions.

\section{ACKNOWLEDGMENT}

This research was supported by three research grants to Reinhard Pekrun from the German Research Foundation (Pe $320 / 7-2,320 / 7-3,320 / 11-1)$ and by a grant to Reinhard Pekrun and Raymond P. Perry from the German American Academic Council.

\section{REFERENCES}

Abela, J. R. Z., \& Seligman, M. E. P. (2000). The hopelessness theory of depression: A test of the diathesis-stress component in the interpersonal and achievement domains. Cognitive Therapy and Research, 24, 361-378.

Astleitner, H. (2000). Designing emotionally sound instruction. Instructional Science, 28, 169-198.

Bandura, A., \& Cervone, D. (1983). Self-evaluative and self-efficacy mechanisms governing the motivational effects of goal systems. Journal of Personality and Social Psychology, 45, 1017-1028.

Barrera, A. (2001). Students' conceptions of intelligence, emotions, and achievement in university statistics courses. Unpublished master's thesis, University of Munich, Germany.

Bless, H., Clore, G. L., Schwarz, N., Golisano, V., Rabe, C., \& Wölk, M. (1996). Mood and the use of scripts: Does a happy mood really lead to 
mindlessness? Journal of Personality and Social Psychology, 71, 665-679.

Boekaerts, M. (1993). Anger in relation to school learning. Learning and Instruction, 3, 269-280.

Covington, M. V. (1992). Making the grade: A self-worth perspective on motivation and school reform. New York: Cambridge University Press.

Ellis, H. C., \& Ashbrook, P. W. (1988). Resource allocation model of the effect of depressed mood states on memory. In K. Fiedler \& J. Forgas (Eds.), Affect, cognition, and social behavior (pp. 25-43). Toronto, Ontario, Canada: Hogrefe International.

Fredrickson, B. L. (2001). The role of positive emotions in positive psychology: The broaden-and-build theory of positive emotions. American Psychologist, 56, 218-226.

Goetz, T., Pekrun, R., Perry, R. P., \& Hladkyi, S. (2001). Academic Emotions Questionnaire: Codebook for English-language scale versions (Tech. Rep.). Munich, Germany: University of Munich, Department of Psychology.

Hatfield, E., Cacioppo, J. T., \& Rapson, R. L. (1994). Emotional contagion. New York: Cambridge University Press.

Hembree, R. (1988). Correlates, causes, effects, and treatment of test anxiety. Review of Educational Research, 58, 47-77.

Hodapp, V., \& Benson, J. (1997). The multidimensionality of test anxiety: A test of different models. Anxiety, Stress and Coping, 10, 219-244.

Lazarus, R. S., \& Folkman, S. (1987). Transactional theory and research on emotions and coping. European Journal of Personality, 1, 141-169.

Levine, L. J., \& Burgess, S. L. (1997). Beyond general arousal: Effect of specific emotions on memory. Social Cognition, 15, 157-181.

Ma, X. (1999). A meta-analysis of the relationship between anxiety toward mathematics and achievement in mathematics. Journal for Research in Mathematics Education, 30, 520-540.

Mandler, G., \& Sarason, S. B. (1952). A study of anxiety and learning. Journal of Abnormal and Social Psychology, 47, 166-173.

Meece, J. L., Wigfield, A., \& Eccles, J. S. (1990). Predictors of math anxiety and its influence on young adolescents' course enrollment intentions and performance in mathematics. Journal of Educational Psychology, $82,60-70$.

Meinhardt, J., \& Pekrun, R. (in press). Attentional resource allocation to emotional events: An ERP study. Cognition and Emotion.

Olafson, K. M., \& Ferraro, F. R. (2001). Effects of emotional state on lexical decision performance. Brain and Cognition, 45, 15-20.

Patrick, B. C., Skinner, E. A., \& Connell, J. P. (1993). What motivates children's behavior and emotion? Joint effects of perceived control and autonomy in the academic domain. Journal of Personality and Social Psychology, 65, 781-791.

Pekrun, R. (1991). Prüfungsangst und Schulleistung: Eine Längsschnittanalyse [Test anxiety and academic achievement: A longitudinal analysis]. Zeitschrift für Pädagogische Psychologie, 5, 99-109.

Pekrun, R. (1992a). Expectancy-value theory of anxiety: Overview and implications. In D. G. Forgays, T. Sosnowski, \& K. Wrzesniewski (Eds.), Anxiety: Recent developments in self-appraisal, psychophysiological and health research (pp. 23-41). Washington, DC: Hemisphere.

Pekrun, R. (1992b). The impact of emotions on learning and achievement: Towards a theory of cognitive/motivational mediators. Applied Psychology, 41, 359-376.

Pekrun, R. (1992c). Kognition und Emotion in studienbezogenen Lern- und Leistungssituationen: Explorative Analysen [Cognition and emotion in academic situations of learning and achievement: Exploratory analyses]. Unterrichtswissenschaft, 20, 308-324.

Pekrun, R. (1998). Schüleremotionen und ihre Förderung: Ein blinder Fleck der Unterrichtsforschung [Students' emotions: A neglected topic of educational research]. Psychologie in Erziehung und Unterricht, 44, 230-248.

Pekrun, R. (2000). A social cognitive, control-value theory of achievement emotions. In J. Heckhausen (Ed.), Motivational psychology of human development (pp. 143-163). Oxford, England: Elsevier.
Pekrun, R., \& Frese, M. (1992). Emotions in work and achievement. In C. L. Cooper \& I. T. Robertson (Eds.), International review of industrial and organizational psychology (Vol. 7, pp. 153-200). Chichester, England: Wiley.

Pekrun, R., Hochstadt, M., \& Kramer, K. (1996). Prüfungsemotionen, Lernen und Leistung [Test emotions, learning, and achievement]. In C. Spiel, U. Kastner-Koller, \& P. Deimann (Eds.), Motivation und Lernen aus der Perspektive lebenslanger Entwicklung (pp. 151-162). Münster, Germany: Waxmann.

Pekrun, R., \& Hofmann, H. (1999). Lern- und Leistungsemotionen: Erste Befunde eines Forschungsprogramms [Emotions in learning and achievement: First results of a program of research]. In R. Pekrun \& M. Jerusalem (Eds.), Emotion, Motivation und Leistung (pp. 247-267). Göttingen, Germany: Hogrefe.

Pekrun, R., Molfenter, S., Titz, W., \& Perry, R. P. (2000, April). Emotion, learning, and achievement in university students: Longitudinal studies. Paper presented at the annual meeting of the American Educational Research Association, New Orleans, LA.

Perry, R. P. (1991). Perceived control in college students: Implications for instruction in higher education. In J. Smart (Ed.), Higher education: Handbook of theory and research (Vol. 7, pp. 1-56). New York: Agathon.

Perry, R. P., Hechter, F. I., Menec, V. H., \& Weinberg, L. (1993). Enhancing achievement motivation and performance in college students: An attributional retraining perspective. Research in Higher Education, 34, 687-720.

Perry, R. P., Hladkyj, S., Pekrun, R., \& Clifton, R. (2001, April). Self-regulation in college students' scholastic attainment: A three-year field study involving academic control and action control. Paper presented at the annual meeting of the American Educational Research Association, Seattle, WA.

Perry, R. P., Hladkyj, S., Pekrun, R., \& Pelletier, S. T. (2001). Academic control and action control in the achievement of college students: A longitudinal field study. Journal of Educational Psychology, 93, 776-789.

Perry, R. P., \& Magnusson, J.-L. (1989). Causal attributions and perceived performance: Consequences for college students' achievement and perceived control in different instructional conditions. Journal of Educational Psychology, 81, 164-172.

Perry, R. P., \& Penner, K. S. (1990). Enhancing academic achievement in college students through attributional retraining and instruction. Journal of Educational Psychology, 82, 262-271.

Perry, R. P., Schonwetter, D., Magnusson, J.-L., \& Struthers, W. (1994). Use of explanatory schemas and the quality of college instruction: Some evidence for buffer and compensation effects. Research in Higher Education, 35, 349-371.

Pintrich, P. R., Smith, D. A. F., Garcia, T., \& McKeachie, W. (1993). Reliability and predictive validity of the Motivated Strategies for Learning Questionnaire (MSLQ). Educational and Psychological Measurement, $53,801-813$.

Rhodewalt, F., \& Morf, C. C. (1998). On self-aggrandizement and anger: Temporal analysis of narcissism and affective reactions to success and failure. Journal of Personality and Social Psychology, 74, 672-685.

Roseman, I. J., Antoniou, A. A., \& Jose, P. E. (1996). Appraisal determinants of emotions: Constructing a more accurate and comprehensive theory. Cognition and Emotion, 10, 241-277.

Ruthig, J. C., Hladkyj, S., Hall, N. C., Pekrun, R., \& Perry, R. P. (2002, April). Profiling voluntary course withdrawal among college students: A longitudinal study with motivational implications. Paper presented at the annual meeting of the American Educational Research Association, New Orleans, LA.

Sarason, I. G. (1984). Stress, anxiety, and cognitive interference: Reactions to tests. Journal of Personality and Social Psychology, 44, 929-938.

Scherer, K. R. (1984). On the nature and function of emotion: A component process approach. In K. R. Scherer \& P. Ekman (Eds.), Approaches to emotion (pp. 293-317). Hillsdale, NJ: Lawrence Erlbaum Associates, Inc. 
Scherer, K. R., Wallbott, H. G., \& Summerfield, A. B. (1986). Experiencing emotion: A cross-cultural study. Cambridge, England: Cambridge University Press.

Schmitz, B., \& Skinner, E. (1993). Perceived control, effort, and academic performance: Interindividual, intraindividual, and multivariate time series analyses. Journal of Personality and Social Psychology, 64, $1010-1028$

Schnabel, K. (1998). Prüfungsangst und schulisches Lernen [Test anxiety and learning at school]. Münster, Germany: Waxmann.

Schutz, P., \& Davis, H. A. (2000). Emotions and self-regulation during test taking. Educational Psychologist, 35, 243-256.

Smith, D. C., Furlong, M., Bates, M., \& Laughlin, J. D. (1998). Development of the Multidimensional School Anger Inventory for males. Psychology in the Schools, 35, 1-15.

Spangler, G., Pekrun, R., Kramer, C., \& Hofmann, H. (in press). Students' emotions, physiological reactions, and coping at exams. Anxiety, Stress and Coping.

Stengel, E. (1936). Prüfungsangst und Prüfungsneurose [Test-related anxiety and neurosis]. Zeitschrift für psychoanalytische Pädagogik, 10, 300-320.

Titz, W. (2001). Emotionen von Studierenden in Lernsituationen [University students' emotions at learning]. Münster, Germany: Waxmann.
Turner, J. E., \& Schallert, D. (2001). Expectancy-value relationships of shame reactions and shame resiliency. Journal of Educational Psychology, 93, 320-329.

Turner, J. C., Thorpe, P. K., \& Meyer, D. K. (1998). Students' reports of motivation and negative affect: A theoretical and empirical analysis. Journal of Educational Psychology, 90, 758-771.

Watson, D., \& Clark, L. A. (1992). Affects separable and inseparable: On the hierarchical arrangement of the negative affects. Journal of Personality and Social Psychology, 62, 489-505.

Weiner, B. (1985). An attributional theory of achievement motivation and emotion. Psychological Review, 92, 548-573.

Weiner, B. (1995). Judgments of responsibility: A foundation for a theory of social conduct. New York: Guilford.

Weinert, F. E., \& Helmke, A. (Eds.). (1997). Entwicklung im Grundschulalter [Development in elementary school children]. Weinheim, Germany: Beltz.

Winteler, A., Schiefele, U., Krapp, A., \& Wild, K.-P. (1991). Skalen zu Studienintresse und Lernstrategien im Studium [Scales on study interest and learning strategies (Tech. Rep.)]. Neubiberg/Munich, Germany: University of the German Army.

Zeidner, M. (1998). Test anxiety: The state of the art. New York: Plenum.

Ziegler, C. (2001). Analysis of emotions, personality variables, social environments, and drop-out rates in university students. Unpublished master's thesis, University of Munich, Munich, Germany. 